\title{
Der Impfstoff
}

Liebe Leserin, lieber Leser,

die Corona-Krise reduziert die globalen $\mathrm{CO}_{2}$-Emissionen. Das gilt aber nicht unbedingt für $\mathrm{NO}_{\mathrm{x}}$ und Feinstaub, wie die Messwerte in mehreren deutschen Städten zeigen. In den letzten Jahren waren Fahrverbote eines der Top-Themen der Mobilitätspolitik. Die CoronaKrise bietet nun die Möglichkeit, deren Wirksamkeit zu überprüfen, denn der Individualverkehr ging erheblich zurück. Es scheint, als hätten moderne Verbrennungsmotoren mit funktionierender Abgasnachbehandlung keinen so starken Einfluss auf die Luftqualität in Ballungsräumen wie bisher angenommen. Andere Verursacher und das Wetter spielen wohl eine deutlich größere Rolle.

Dennoch geht es nach wie vor nur um E-Mobilität als Zukunftstechnologie. Eine jetzt veröffentlichte Studie des Leibniz-Instituts für Wirtschaftsforschung und der Yale-Universität schlägt in diese Kerbe und postuliert gar, eine falsche Annahme der Kosten eines Pkws seitens der Verbraucher würde die Mobilitätswende hemmen und alternative Angebote wie E-Autos und ÖPNV weniger attraktiv machen. Das Credo der Forscher: Mehr Kostentransparenz würde die nachhaltige Verkehrswende beschleunigen. Es ist zu vermuten, dass die Verfasser nahezu ausschließlich in großen Ballungszentren mit umfassendem ÖPNV-Angebot leben und über ein deutlich überdurchschnittliches Grundeinkommen verfügen. Viele Länder haben aber keine Ballungszentren, sondern ausgedehnte ländliche Gebiete. Dort stellt sich weniger die Frage der Kosten für individuelle Mobilität, sondern: Wie komme ich überhaupt von A nach B? Und dies geht dort zumeist nur mit dem privaten Pkw. Hinzu kommt, dass bei einem durchschnittlichen Bruttoverdienst von 3880 Euro im Monat in Deutschland 2019 für viele Normalverbraucher der Kauf eines deutlich teureren E-Autos kein Thema ist. Diese Punkte werden in der Diskussion um eine Verkehrswende zu wenig beachtet.

Die EU und deutsche Top-Politiker fordern einen ökologisch orientierten wirtschaftlichen Neustart nach der CoronaKrise. Das ist prinzipiell richtig und gut. Er muss dann aber auch in puncto Mobilität konsequent, technologieoffen und mit hoher Fachkenntnis umgesetzt werden. Sollen Klimaschutz und Luftreinhaltung global und nachhaltig erfolgen, dann ist die E-Mobilität nicht der Weisheit einziger Schluss. Zwingend ist dann die Öffnung des zusätzlichen Wegs in Richtung synthetische Kraftstoffe. „Beim Klima kennen wir den Impfstoff schon“, sagte Bundesumweltministerin Svenja Schulze kürzlich. Das ist richtig, und ein unabdingbarer Grundstoff hierfür ist die Trias aus batterieelektrischer Mobilität, Wasserstoff- und Brennstoffzellen-getriebenen Fahrzeugen sowie synthetischen Kraftstoffen. Nur so sind die Pariser Klimaziele zu erreichen. Der Schlüssel zur Zukunftsmobilität ist kein Entweder-oder, sondern ein Sowohl-als-auch.

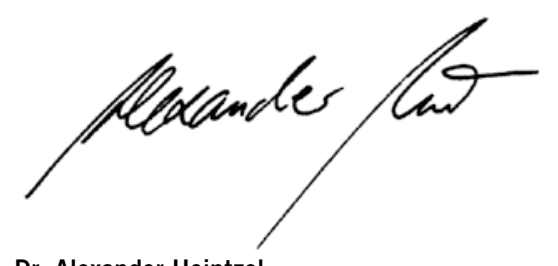

Dr. Alexander Heintzel

Chefredakteur

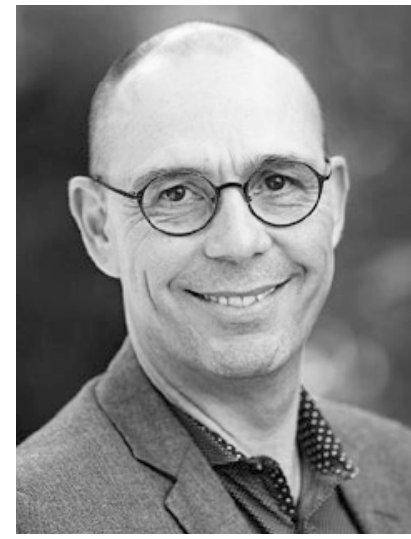

sschlogloch in 500 Meterntu

Wenn Informationen von Auto zu Auto wandern.

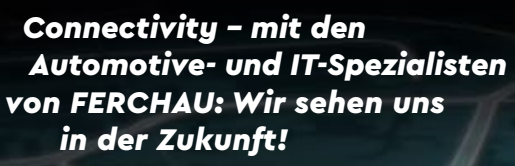

Das Head-up-Display visualisiert Über Augmented Reality Informationen direkt im Sichtfeld

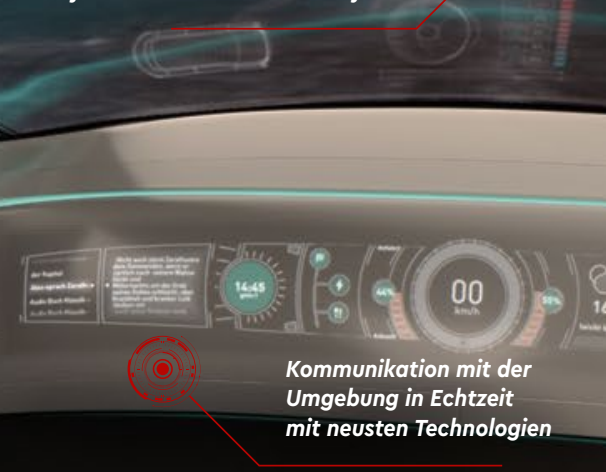

Sprach- und gestengesteuerte Schnittstellen zum Fahrzeug

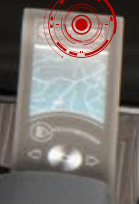

Wir bringen Autos dazu, sich intelligent zu vernetzen und vorausschauend zu handeln. Wir entwickeln Car2X-Software, die automatisch den besten Parkplatz findet und gleich den Restauranttisch reserviert. FERCHAU, Deutschlands Engineeringund IT-Dienstleister Nr. 1, führt Automotive und IT zusammen - für die Car Connectivity der Zukunft. Und gern auch für Ihr Unternehmen! Nehmen Sie Kontakt zu uns auf: Gemeinsam kommen wir weiter.

FERCHAU GmbH, Zentrale info@ferchau.com

\section{ferchau.com/go/zukunft}

